\title{
Incorporating water quantity and quality modelling into forest management
}

\author{
by Xiangfei Liji,2, Mohamed H. Nour ${ }^{3}$, Daniel W. Smith ${ }^{1}$, Ellie E. Prepas ${ }^{4,5}$, Gordon Putz ${ }^{6}$ and Brett M. Watson ${ }^{6}$
}

\begin{abstract}
Under the authority of the Millar Western Forest Products Ltd. (MWFP) Forest Management Agreement, the company has the right to harvest trees, grow trees, manage the forest and plan activities that assure forest productivity and industry profitability without jeopardizing the quality of the environment. Thus, as part of obtaining provincial government approval, the company has to submit a Detailed Forest Management Plan that includes a comprehensive assessment of the environmental implications of forestry operations and the mitigation of impacts. Forest management planning for environmental sustainability will become more and more difficult with increased land use pressures from other industries, agriculture and recreation. Therefore, the planning process will require increasingly more sophisticated modelling tools to identify and avoid significant impacts. The Forest Watershed and Riparian Disturbance (FORWARD) project proposes a hybrid modelling tool that relies on inexpensive remote sensing data, with few ground truthing requirements, to model streamflow, suspended solids and nutrients in streams on the Boreal Plain. Incorporating modelling tools into the MWFP planning process provides MWFP additional strategies to operate in an environmentally sensitive manner. Thus, the company can maintain an allowable cut, while ensuring that ecological and physical values are considered.
\end{abstract}

Key words: forest management and planning, modelling, artificial neural networks, SWAT, remote sensing, MODIS, GIS

\section{RÉSUMÉ}

En fonction des droits accordés par le contrat d’aménagement forestier de Millar Western Forest Products Ltd. (MWFP), lentreprise a la possibilité de couper du bois, de faire pousser des arbres, d’aménager la forêt et de planifier des activités qui assurent la productivité de la forêt et la profitabilité de l'entreprise sans mettre en péril la qualité de l'environnement. Par conséquent, afin d’obtenir l'approbation du gouvernement provincial, l'entreprise doit soumettre un plan d’aménagement forestier détaillé qui inclut une évaluation complète des implications environnementales des opérations forestières et de la mitigation de ces effets. La planification de l'aménagement forestier dans un contexte de durabilité environnementale deviendra de plus en plus difficile avec laccroissement des pressions exercées en matière d'utilisation du territoire de la part des autres industries, de l'agriculture et des activités récréatives. En conséquence, le processus de planification nécessitera de plus en plus l'utilisation d’outils sophistiqués de modélisation afin d'identifier et déviter les impacts significatifs. Le projet Forest Watershed and Riparian Disturbance (FORWARD) propose un outil hybride de modélisation qui repose sur des données de télédétection peu dispendieuses accompagnées de quelques vérifications au sol, permettant de modéliser lécoulement des eaux, les solides en suspension et les éléments nutritifs des cours d’eau de la Plaine boréale. Linclusion des outils de modélisation au processus de planification de MWFP fournit à lentreprise des stratégies additionnelles d’opération respectant le contexte environnemental. Par conséquent, lentreprise peut maintenir le niveau de coupe permis, tout en assurant que les valeurs écologiques et physiques sont prises en considération. .

Mots clés : aménagement forestier et planification, modélisation, réseaux neuronaux artificiels, SWAT, télédétection, MODIS, SIG

\footnotetext{
${ }^{1}$ Department of Civil and Environmental Engineering, 3-133 Markin/CNRL Natural Resources Engineering Facility, University of Alberta, Edmonton, Alberta T6G 2W2.

${ }^{2}$ Author to whom correspondence should be sent. E-mail: xiangfei@ualberta.ca

${ }^{3}$ ISL Engineering and Land Services Ltd., 1007909 - 51 Avenue NW, Edmonton, Alberta T6E 5L9.

${ }^{4}$ Faculty of Forestry and the Forest Environment, Lakehead University, Thunder Bay, Ontario P7B 5E1.

${ }^{5}$ Department of Biological Sciences, University of Alberta, Edmonton, Alberta T6G 2E9.

${ }^{6}$ Department of Civil and Geological Engineering, University of Saskatchewan, 57 Campus Drive, Saskatoon, Saskatchewan S7N 5A9.
} 


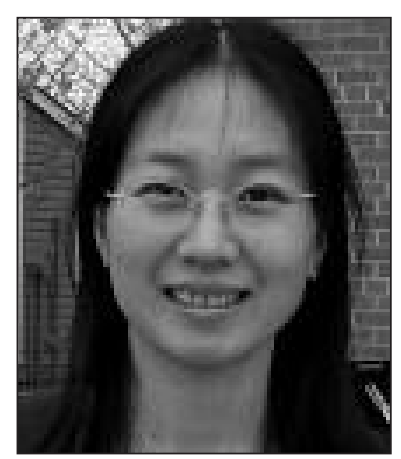

Xiangfei Li

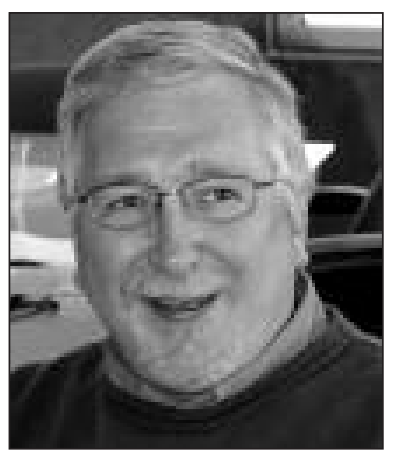

Gordon Putz

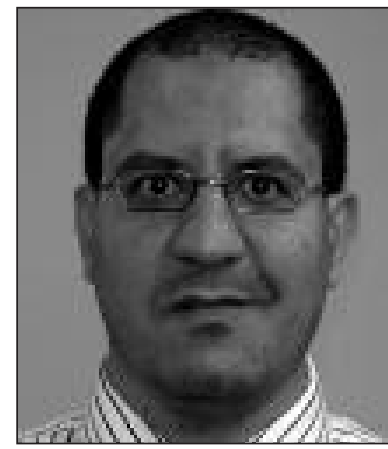

Mohamed H. Nour

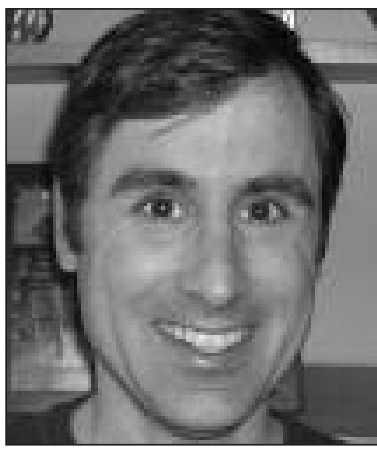

Brett M. Watson

\section{Introduction}

In Alberta, forestry is an important land-based resource activity, following only the oil and gas and agricultural sectors in economic importance. Millar Western Forest Products Ltd. (MWFP) is an Alberta-based company involved in pulp and lumber production. The company's harvesting activities are governed by a Forest Management Agreement (FMA) with the Province of Alberta. The obligations of an FMA permit holder are to harvest no more than the amount of timber stated in the FMA, and to promptly regenerate and maintain the harvested areas in a forested condition. In addition, the FMA holder should also plan its harvest strategy to prevent detrimental effects to other interests in its FMA area. To accommodate possible conflicting interests within an FMA area, the agreement holder prepares a Detailed Forest Management Plan (DFMP) that sets the strategic planning process. This process assures that each FMA holder is following the guidelines set out by the provincial government.

A set of harvesting control policies are currently used as best practices, attempting to minimize the adverse impacts of forest harvesting on biodiversity, ecological integrity, water quantity and quality and timber supply. In an era of increased land use and resource development, forest management planning processes will require increasingly more sophisticated modelling tools and science-based evidence to identify and avoid significant impacts on the environment (Smith et al. 2003a).

As a first step toward developing the required modelling tools, MWFP initiated the Forest Watershed and Riparian Disturbance (FORWARD) project in collaboration with researchers from Lakehead University, the University of

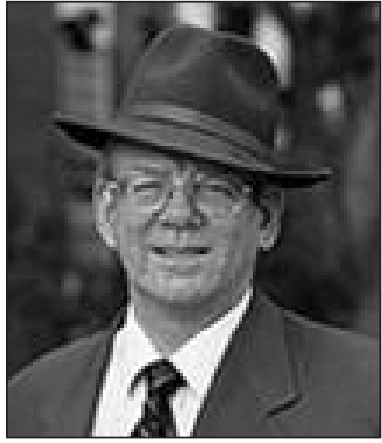

Daniel W. Smith

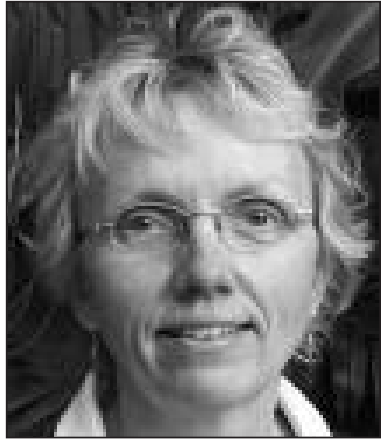

Ellie E. Prepas
Alberta, and the University of Saskatchewan to develop a better understanding of the impact of harvesting activities on soils, hydrology and water quality (Smith et al. 2003b). Over the past six years, FORWARD research has provided a detailed database of soil properties, streamflow and water quality within the MWFP FMA area and a better understanding of the link between land-based activities and water resource impacts. Initial streamflow and water quality simulation models have been formulated and tested on small pilotscale forested watersheds near Whitecourt, Alberta. To apply these models on a scale comparable to an entire industrial forest management area, there is an urgent need to adapt them to be less reliant on data-intensive inputs and to provide the means to include these models in operational forest management and planning. This paper summarizes the available water quantity and quality models, presents the FORWARD stream flow and quality modelling approach and initial modelling results, and proposes a framework toward incorporating these modelling efforts in the DFMP process.

\section{Water Quantity and Quality Modelling}

Simulation models are very useful tools to analyze watershed processes, and to develop and assess watershed management scenarios. A multitude of applications (e.g., streamflow and water quality parameters forecasting, the evaluation of the impact of different forest management and agricultural activities on water quantity and quality and the evaluation of watershed responses to different climate change scenarios) have contributed to the development of a vast number of watershed models, starting in the early 1960s (Wagener 2005). These models are usually a mixture of linear and nonlinear functions, combined to represent those processes occurring in a specific watershed and important for the study objectives at hand.

\section{Review of available watershed models}

Watershed models can be classified based on the degree of spatial resolution into: (1) lumped models that use average values of input variables over the entire watershed area, and thus have minimal data requirements; (2) semi-distributed models that divide the watershed into sub-watersheds, in which each sub-watershed carries a distinct set of input variables; and (3) distributed models that are pixel-based in terms of input representations and parameter routing, and therefore having huge data requirements. Although using distributed models is conceptually appealing, the superiority of the more 
complex semi-distributed and distributed models over the simpler lumped models is still an issue of debate (Wilcox et al. 1990, Michaud and Sorooshian 1994, Hauhs et al. 1996, Donnelly-Makowecki and Moore 1999).

Watershed models can also be classified according to physical conceptualization into: (1) empirical (also called data-driven); (2) physically based (also called mechanistic); and (3) conceptual (also called parametric) models. Empirical models use available time-series of input and output variables (e.g., nutrient concentrations, precipitation, streamflow, temperature) to derive both the model structure and the corresponding parameter values. They therefore do not need a complete prior knowledge about the physical, chemical, hydro-morphological and biological processes controlling flow processes and contaminant transport mechanisms. Physically based models mathematically describe a process using a set of principles, based on the conservation of mass, momentum and energy. They are distributed models and have intensive data requirements. Conceptual models include both simplified physically based components and empirical components. The modeller, based on a conceptualization of the watershed, specifies the structure of these models in advance and uses observations of the watershed response to find appropriate values for the model parameters through empirical relations. Conceptual models form the large majority of models used in practice.

Conceptual watershed-scale water quantity and quality models include, but are not limited to, the Soil and Water Assessment Tool (SWAT) developed by Arnold et al. (1998), aerial non-point source watershed environment simulation2000 (ANSWERS-2000) (Beasley et al. 1980, Bouraoui and Dillaha 1996), Hydrologic Simulation Program Fortran (HSPF) (Johanson et al. 1984), erosion productivity impact calculator (Sharpley and Williams 1990), annualized agriculture non-point source pollutant loading model (AnnAGNPS) (Bingneer et al. 2001), and the Guelph model for evaluating the effects of agricultural management systems on erosion and sedimentation (GAMES) by Cook et al. (1985). The use of this class of models presents the challenge of estimating or calibrating a large number of model parameters from information with limited availability. Obtaining the information necessary for model calibration is time-consuming and expensive.

Data-driven models have been successful in capturing patterns in data with less knowledge of the behaviour of the system in terms of interactions among the biological, geological, chemical and physical processes affecting the modelled system. Consequently, they are attractive alternatives to traditional conceptual models. Among those techniques, artificial neural network (ANN) models hold promise for water quantity and quality modelling. ANN models can often capture data patterns without extensive knowledge of the particular site-related problems and can model complicated and nonlinear processes with fewer input variables than mechanistic models. Since they are capable of handling large-scale and complex problems, ANN models provide great advantages in a wide range of water quality applications, such as modelling sediment concentrations (Cigizoglu and Alp 2006, Cigizoglu and Kisi 2006, Nour et al. 2006b, Tayfur and Guldal 2006, Alp and Cigizoglu 2007), phosphorus concentrations (Nour et al. 2006b, c, d), and cyanobacteria blooms (Maier et al. 2004, Teles et al. 2006) in surface waters.

\section{Data requirements}

Watershed-scale water quality models typically require a considerable amount of data (e.g., topography, vegetation cover, soil characteristics, stream channel characteristics and subsurface infiltration) for model calibration. Providing the money and effort to get this information is infeasible for large land areas, thus hindering the applications of theses models in practice. The current resurgence in earth-observing satellite and airborne platforms, along with the advancements in computer and software technology, has made it possible to evaluate and quantify large numbers of watershed physical characteristics and state variables via remote sensing (RS). It is a cost-efficient way to improve the spatial and temporal coverage of surface water and watershed monitoring (Koponen et al. 2004). RS techniques have expanded widely, to the point that they now include most of the electromagnetic spectrum. Different sensors can provide unique information about properties of the surface or shallow layers of the Earth.

The application of RS information to watershed modelling, as well as management, can be divided into three main categories: (1) to delineate surface features, such as snow-covered areas, surface water extent or sediment plumes; (2) to retrieve information such as land cover, geological features or other hydrologic parameters through interpretation and computer classification of remotely sensed data; and (3) to directly use RS digital data to estimate hydrological state parameters. The third application is the most important to watershed modelling and is normally achieved through electro-optical or statistical modelling of known hydrometric data with satellite data. Although there has been some success in the application of RS data in hydrology, the incorporation of RS information in watershed water quality modelling still requires more effort.

The Moderate-resolution Imaging Spectroradiometer (MODIS) sensor on board the earth-monitoring satellite Terra (United States National Aeronautics Space Administration [NASA]) allows for measurement of plant growth on a global scale at moderate spatial and temporal resolution. The data provided by the MODIS Land Group (e.g., vegetation indexes (VIs) like the normalized difference vegetation index (NDVI), enhanced vegetation index (EVI) and leaf area index (LAI)) support global to regional monitoring, modelling and assessment (Justice et al. 1998, NASA 2007, Li et al. 2008). Furthermore, MODIS data are freely available, thus providing a means of acquiring time series representations of vegetation dynamics at an affordable cost. For instance, a successful nutrient model requires information regarding soil and vegetation nutrient status. RS VIs can represent vegetation health and stress in terms of the vegetation chlorophyll content and the leaf water content, which can be linked to soil/vegetation nutrient interactions and thus can aid in formulating relatively accurate and usable nutrient watershed models (Cheng et al. 2006). Such information can potentially act as a surrogate for soil/vegetation nutrient transport and therefore can potentially represent vegetation dynamics in nutrient model formulation.

\section{Integration of RS and GIS with simulation models for watershed management}

The complexity of decision-making, as well as data requirements, has created a need to integrate RS and Geographical Information Systems (GIS) technology with simulation mod- 
els for watershed management. GIS technology is an essential tool in a variety of fields where spatial information processing is involved, such as forest management, urban planning and agriculture. RS is commonly used in conjunction with GIS to provide spatial data in GIS databases. GIS and RS have been combined with simulation models for many applications, such as vegetation mapping and monitoring, biodiversity mapping and modelling, hydrological modelling, land use planning and environmental impact assessment (Skidmore 2002). For example, a GIS-based ANN model was developed to simulate spatial distribution of nitrate $\left(\mathrm{NO}_{3}{ }^{-}\right)$concentrations in groundwater with land use information and site-specific hydrogeological properties in an agricultural region (Wang et al. 2006). GIS tools were used to prepare and process input-output vectors data for the ANN, which efficiently simulated groundwater $\mathrm{NO}_{3}{ }^{-}$concentrations and captured the general trend of groundwater $\mathrm{NO}_{3}{ }^{-}$pollution patterns (Wang et al. 2006). The use of multi-temporal RS images in support of environmental modelling analysis in a GIS environment has contributed to identify a variety of long-term interactions between resources and land use (Ning et al. 2006). The spatial and temporal variation in $\mathrm{NO}_{3}{ }^{-}$in the basin of a small river was simulated by combining $\mathrm{NO}_{3}{ }^{-}$dynamic modelling and GIS with the use of RS NDVI (Matejicek et al. 2003). The NDVI was implemented in the dynamic model to estimate the level of denitrification. In summary, the integration of simulation models, GIS techniques and RS information is necessary to improve watershed management and decisionmaking processes when ground-based data are limited.

\section{FORWARD Modelling Approach}

The FORWARD project study area includes 16 watersheds (3 to $250 \mathrm{~km}^{2}$ ) located in the Virginia Hills, Alberta (locations shown in Prepas et al. 2008). Seven of the watersheds are relatively undisturbed systems, four were up to $100 \%$ burned during the Virginia Hill fire in 1998, four were harvested in 2004, and one was harvested in 2000. Data collection on soil, vegetation, meteorology, water quantity and water quality began in 1998. Based on 11 selection criteria for modelling streamflow and nutrient concentrations in Boreal Plain streams, two modelling approaches incorporating the SWAT model and ANNs have been used in the FORWARD Project (Putz et al. 2003). A detailed description of the FORWARD Project can be found in the Journal of Environmental Engineering and Science 2 (Supplement S1).

\section{SWAT modelling}

The SWAT model is a physically based distributed watershedscale model that operates on a daily time step. It was developed to predict the impact of watershed management on water, sediment, nutrient and agricultural yields in large basins for a long simulation period (Arnold et al. 1998). Spatially, the SWAT model simulates a basin by subdividing it into sub-basins based on topographic information. The components of sub-basins include eight major divisions: hydrology, weather, sedimentation, soil temperature, crop growth, nutrients, pesticides and agricultural management (Arnold et al. 1998). The sub-basins can be further divided into smaller modelling units called Hydrologic Response Units (HRUs) depending on the heterogeneity of land uses and soil types within the sub-basin (Muleta and Nicklow 2005). Watershed characteristics and management features are considered homogeneous within an HRU.

Hydrologic processes are simulated within the SWAT model, including surface runoff, percolation, lateral subsurface flow, groundwater flow, snowmelt and water storage (Arnold et al. 1998). The SWAT model also simulates a variety of other watershed processes (e.g., crop growth and nutrient cycling) using watershed information like weather, soil, topography, vegetation and land management practices. The integration of GIS and the SWAT model has proven to be an effective and efficient means for input data preprocessing and output data visualization (Arnold et al. 1999). It has been successfully used for many case studies (Di Luzio et al. 2005, Qi and Grunwald 2005, Santhi et al. 2005, Grunwald and Qi 2006, Olivera et al. 2006). The SWAT model is a comprehensive hydrologic model that can simulate streamflow, as well as water quality parameters. It is a public-domain model and is conceptually sound. However, it was initially developed to simulate agricultural watersheds. A number of modifications are required for the model to be able to simulate a forested ecosystem.

\section{ANN modelling}

An ANN model is a data-driven modelling alternative that was developed in an attempt to mimic the learning of human brains. ANNs consist of a large number of simple, highly interconnected processing elements (neurons) in an architecture inspired by the structure of the cerebral cortex of the brain (Tsoukalas and Uhrig 1997). The successful application of ANNs in water quantity and quality modelling indicates that ANN models are useful in supporting environmental decision-making (Maier et al. 2001, Rudra et al. 2005, Dakou et al. 2006, Diamantopoulou et al. 2007, Elhatip and Komur 2008).

There are seven major components to an ANN architecture: (1) processing neurons, (2) a state of activation, (3) an output function for each neuron, (4) a pattern of connectivity or weights between neurons, (5) a propagation rule, (6) an activation function to combine the inputs impinging on a neuron with the current state of that neuron to produce a new level of activation for that unit, and (7) a learning rule whereby weights are adjusted for model calibration (Rumelhart and McClelland 1986). The processing neurons are generally organized in layers. The multi-layer perceptron neural network trained with the error back-propagation training algorithm (MLP-BP) is by far the most popular of all neural networks (Maier and Dandy 2000, Dawson and Wilby 2001). Considering the popularity of the algorithm and because the authors have applied this algorithm successfully in different applications, it was used in this study.

The development of ANN models generally includes the following steps: (1) input determination; (2) data division into training, testing and validation datasets; (3) determination of model architecture (e.g., number of hidden layers, number of neurons in each layer, activation function, and learning rate); (4) model calibration; and (5) model evaluation. The determination of model inputs is one of the most important steps in developing a successful ANN model. Training data quality is of paramount importance to a data-driven modelling approach like ANN. Inclusion of noisy and correlated input variables can increase computational complexity and deteriorate model performance. Thus, input variables should be 
carefully selected to closely describe the physical system being modelled. Ideally, the available input/output data pairs should be divided into three data sets for training (calibrating), testing and validating the model. The training data set is used for model training and for the optimization of the model connection weights. The testing set is used to decide when to stop training to avoid model overfitting. The cross-validation data set is used to evaluate the model against a totally independent data set. Careful data division is important to assure good model generalization ability. Model architecture determination generally relies upon modellers' experience; however, guidelines have been proposed in recent studies (e.g., Maier and Dandy 2000, Nour et al. 2006d). For an ANN to generate output predictions that are as close as possible to the objective values, model calibration is an essential step to find optimal weights, minimizing a predetermined error function. After model calibration, the power of the models in terms of prediction accuracy, robustness and generalization ability should be verified before the models are put in use. The models usually are tested through several criteria including: the coefficient of multiple determination $\left(R^{2}\right)$, correlation coefficient, root mean squared error, the multivariate corrected Akaike's information criterion (AICc), the Bayesian information criterion (BIC), swapping the testing and validation data sets, plotting measured and predicted values over time and graphing measured and predicted values for training, testing and validation data sets (Nour et al. 2008a).

\section{Link between SWAT and ANN}

The SWAT model is widely used for hydrologic processes simulation and to support decision-making within watershed management. It has been upgraded over time and integrated with a GIS database component. However, as a physically based distributed basin scale model, the SWAT model is very data intensive. In some situations, the power of SWAT is compromised due to data limitation. On the other hand, ANNs are able to identify the relationship between inputs and outputs, without fully understanding the mechanistic principles behind them. ANN models have proved to be superior to mechanistic models when data are limited and numerous assumptions have to be made to solve the physically based equations. For instance, in-stream nitrogen concentrations, which are affected by land use/land classification, vegetation dynamics and in-stream nitrogen transformations, were simulated reasonably well with the ANN approach (Lek et al. 1999, Khalil et al. 2005).

A study comparing the performance of SWAT and ANN models in simulating hydrologic processes in an agricultural watershed found that the ANN monthly predictions were closer to the observed flows than the monthly predictions from the SWAT model (Srivastava et al. 2006). This and other studies suggest that ANN is an attractive modelling alternative for hydrologic and water quality modelling. However, current ANNs efforts cannot take into account spatial variation within a watershed. More efforts are needed to explore the applicability of developing semi-distributed watershed models using ANN.

There have been very limited attempts in the literature to develop a hybrid SWAT/ANN approach. For example a hybrid rainfall-runoff model integrating ANNs with a conceptual model was introduced by Chen and Adams (2006). In their hybrid model, the spatial variation of rainfall, the heterogeneity of watershed characteristics and their impacts on runoff were investigated by the semi-distributed conceptual rainfall-runoff model, while the nonlinear transformations of the runoff generated from the individual subcatchments into the total runoff at the watershed outlet were performed by the ANNs. This hybrid model took into account both the spatial variation presented by the semi-distributed conceptual model and the nonlinear mapping ability of ANNs, highlighting the possibility of integrating the two kinds of models.

FORWARD researchers use one physically based dataintensive approach to understand the biological, geological, chemical and physical behaviours of the system, and one data-driven approach that is flexible in terms of data requirements to develop a modelling tool that is less data-intensive. In addition, attempts to link both the SWAT and the ANN approaches are ongoing to capitalize on the strength of each technique.

\section{Initial Modelling Results}

To date, FORWARD researchers have made significant modifications to the SWAT model to better model watersheds located in forested ecosystems. More modifications are underway. They developed a step-by-step framework for modelling time-correlated variables using ANN and a protocol for utilizing RS information in water quality modelling, and they have applied the developed models successfully in experimental small watersheds in the Boreal Plain. Both these modelling efforts require significant additional advancements before they can to be applied to a larger landbase (like an FMA area) due to the lack of detailed distributed landbase data. The experience gained from implementing ANN and SWAT models in small experimental watersheds will pave the road for further development towards a robust technique for utilizing RS data at the wider FMA scale. The following sections summarize the conducted modifications for the SWAT model, and the initial results of the ANN modelling approach.

\section{Modification of SWAT}

Because the SWAT model was originally developed for agricultural watershed management, a series of modifications have been incorporated to make it effective for boreal forest management. The modified model, called SWAT-Boreal Forest (SWAT-BF), incorporates the following major changes:

1. A litter layer component adopted from Wattenbach et al. (2005) has been incorporated. The litter layer contains many nutrients and is an important component of forest ecosystem. It is able to store water and reduce peak flows during rain events.

2. An algorithm was incorporated to account for the effects of slope and aspect on incoming solar radiation.

3. A new wetlands model was incorporated, since the original wetlands model was not deemed suitable for the wetlands found in boreal forests. The new wetlands model is based on a bucket model approach. It has an upper organic layer and a lower organic layer. A non-linear function is used to determine the amount of lateral flow from each layer. Unlike the original wetlands model in SWAT, the new model accounts for water uptake by vegetation, surface runoff, percolation and base flow. 
4. A new feature has been incorporated into SWAT that enables lateral flow and base flow from upland HRUs to be routed through lowland wetlands that are found in valley bottoms. Previously with SWAT, this was not possible. Instead, all HRUs simply contributed to the stream and there was no consideration of the position of the HRUs in the landscape. Lowland wetlands tend to retain water and dampen peak flows, so this new arrangement in SWAT attempts to reproduce that process.

\section{ANN modelling of streamflow and water quality parameters} The FORWARD researchers have been successful in using ANN modelling to predict streamflow, and water-phase total suspended solids (TSS), total phosphorus (TP), and nitrogen components $\left(\mathrm{NO}_{3}{ }^{-}\right.$and total dissolve nitrogen (TDN)) in undisturbed FORWARD watersheds (e.g., Willow, Two Creek, and Cassidy), disturbed watersheds (e.g., Burnt Pine) and watersheds with a relatively large percentage of wetlands (e.g., 1A) (Table 1). The main advantage of the developed ANN models is that they use as inputs meteorological data, which are easily accessible in the boreal forest via Environment Canada weather stations and provincial fire towers, and public-domain, free-of-cost RS MODIS-derived VIs. The model inputs were carefully selected to reflect causality, time correlation and Q/TSS/nutrient hystereses loops. The inputs are composed of cause/effect factors (e.g., rainfall (R), snowfall (S), temperature (T), degree-days (dd), and EVI), timelagged inputs (e.g., $R_{t}, R_{t-1}, \ldots R_{t-\mathrm{N}}$ ) and inputs reflecting seasonal cyclisity and Q/TSS/nutrient hystereses behaviour (e.g., $\sin (2 \pi v t), \cos (2 \pi v t)$, Julian day), which are determined based on a combination of prior knowledge of the system being modelled, as well as statistical analysis of the data (Table 1).

The developed models predictions compared well with the validation data results $\left(R^{2}\right.$ of validation $\left.>0.76\right)$, which highlights the good generalization ability of these models. Also, they captured the seasonal cycle of the modelled parameters and accurately predicted both base and peak concentrations (see Fig. 1 as an example).

To quantify the impact of land use activities on water quality, the model must divide the watershed into sub-watersheds, to be able to recognize the locations of disturbances and hence simulate the corresponding impacts. FORWARD researchers conducted a leading study on the impact of watershed subdivision on the prediction accuracy of TP concentration in Boreal Plain streams (Nour et al. 2008b). Although the statistical model evaluation favoured the finest spatial resolution, all model performance indicators were satisfactory for the four models devised for different watershed subdivisions for the Willow watershed. The differences in performance indicators were not significant for any practical application. Therefore, it was concluded that the choice of the optimum watershed subdivision should depend upon the modelling objective (Nour et al. 2008b). Lumped parameter models are easy to construct and rely on affordable landbase information, but cannot address questions related to the impact of different land use scenarios on water quality. Therefore, if the objective is to forecast real-time water quality (likely used for post-harvesting assessment), lumped parameter modelling can be used without jeopardizing prediction accuracy. On the other hand, if the objective is to quantify the impact of different land use activities, then the watershed must be divided into sub-watersheds to make the model able to recognize the locations of disturbances and, thus, able to simulate the corresponding impacts on water quality. Based on our results, we conclude that only in this case is the added time, cost and effort of preparing and processing distributed landbase information justifiable.

Successful ANN modelling of water quantity and quality parameters relying only on meteorological and RS data suggests that the proposed models can potentially be applied to

Table 1. Initial ANN modelling results for streamflow and water quality parameters.

\begin{tabular}{|c|c|c|c|c|c|}
\hline \multirow{2}{*}{$\begin{array}{l}\text { Modelled } \\
\text { parameter }\end{array}$} & \multirow{2}{*}{$\begin{array}{l}\text { FORWARD } \\
\text { watershed }^{\mathrm{a}}\end{array}$} & \multirow[b]{2}{*}{ Input parameters } & \multicolumn{2}{|c|}{ Model performance $\left(R^{2}\right)$} & \multirow[b]{2}{*}{ References } \\
\hline & & & Calibration & Validation & \\
\hline Q & $\begin{array}{l}\text { Cassidy, Willow, } \\
\text { 1A, Two Creek }\end{array}$ & $\begin{array}{l}\mathrm{R}^{\mathrm{b}}, \mathrm{dd}^{\mathrm{b}}, \mathrm{S}^{\mathrm{b}}, \mathrm{T}^{\mathrm{b}}, \text { seasonal cycle indicators } \\
(\sin (2 \pi v t), \cos (2 \pi v t))\end{array}$ & $>0.90$ & $>0.84$ & $\begin{array}{l}\text { Nour et al. } \\
\text { 2006b, c, 2008a }\end{array}$ \\
\hline TSS & Two Creek & $\begin{array}{l}\mathrm{R}, \mathrm{dd}, \mathrm{S} \text {, seasonal cycle indicators } \\
(\sin (2 \pi v t), \cos (2 \pi v t))\end{array}$ & $>0.90$ & $>0.90$ & Nour et al. 2006b \\
\hline $\mathrm{TP}$ & $\begin{array}{l}\text { Willow, 1A, } \\
\text { Two Creek }\end{array}$ & $\begin{array}{l}\mathrm{R}, \mathrm{dd}, \mathrm{S}, \mathrm{T}, \mathrm{EVI}^{\mathrm{b}} \text {, and seasonal cycle indicators } \\
(\sin (2 \pi v t), \cos (2 \pi v t))\end{array}$ & $>0.86$ & $>0.76$ & $\begin{array}{l}\text { Nour et al. 2005; } \\
\text { Nour et al. 2006b, } \\
2008 b\end{array}$ \\
\hline $\mathrm{TDN}$ & $\begin{array}{l}\text { Willow, Two Creek, } \\
\text { Burnt Pine }\end{array}$ & $\mathrm{R}$, dd, T, EVI, seasonal cycle indicator (Julian day) & $>0.90$ & $>0.90$ & Li et al. 2008 \\
\hline $\mathrm{NO}_{3}^{-}$ & $\begin{array}{l}\text { Willow, Two Creek, } \\
\text { Burnt Pine }\end{array}$ & R, dd, T, EVI, seasonal cycle indicator (Julian day) & $>0.90$ & $>0.90$ & Li et al. 2008 \\
\hline $\mathrm{NH}_{4}^{+}$ & $\begin{array}{l}\text { Willow, Two Creek, } \\
\text { Burnt Pine }\end{array}$ & R, dd, T, EVI, seasonal cycle indicator (Julian day) & $>0.90$ & $>0.83$ & Li et al. 2008 \\
\hline
\end{tabular}

${ }^{a}$ Cassidy, Willow and Two Creek are undisturbed watersheds, 1A is undisturbed and has a large percentage of wetlands, Burnt Pine watershed was $100 \%$ burned in 1998

bR: rainfall, dd: degree-days, S: snowfall, T: air temperature, EVI: enhanced vegetation index. 


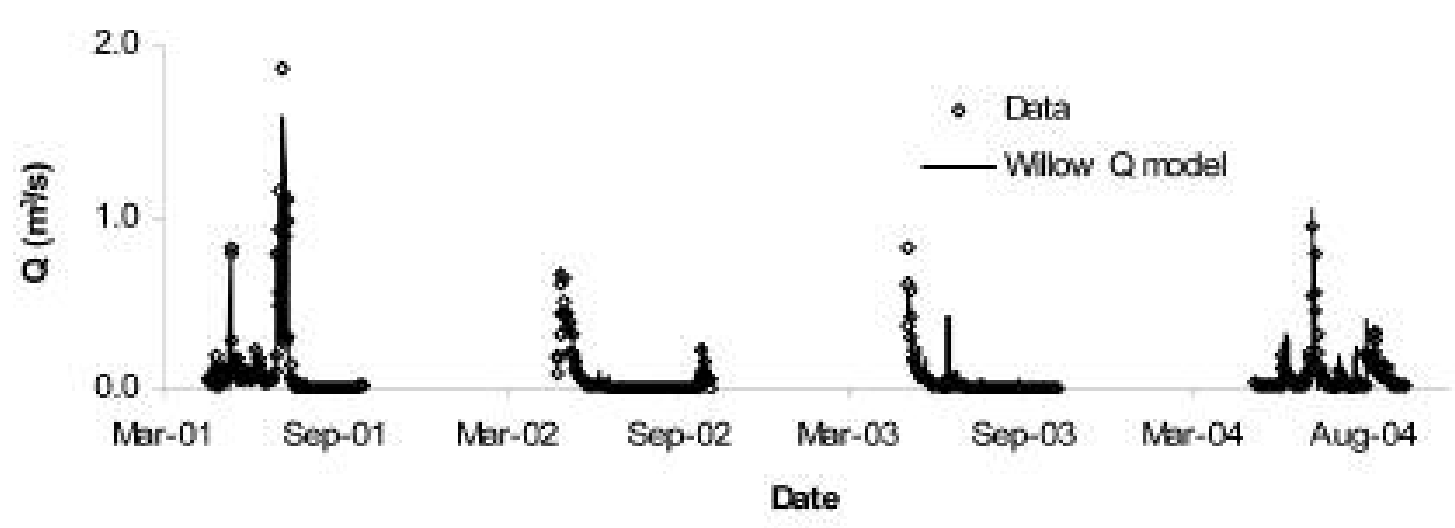

(a)

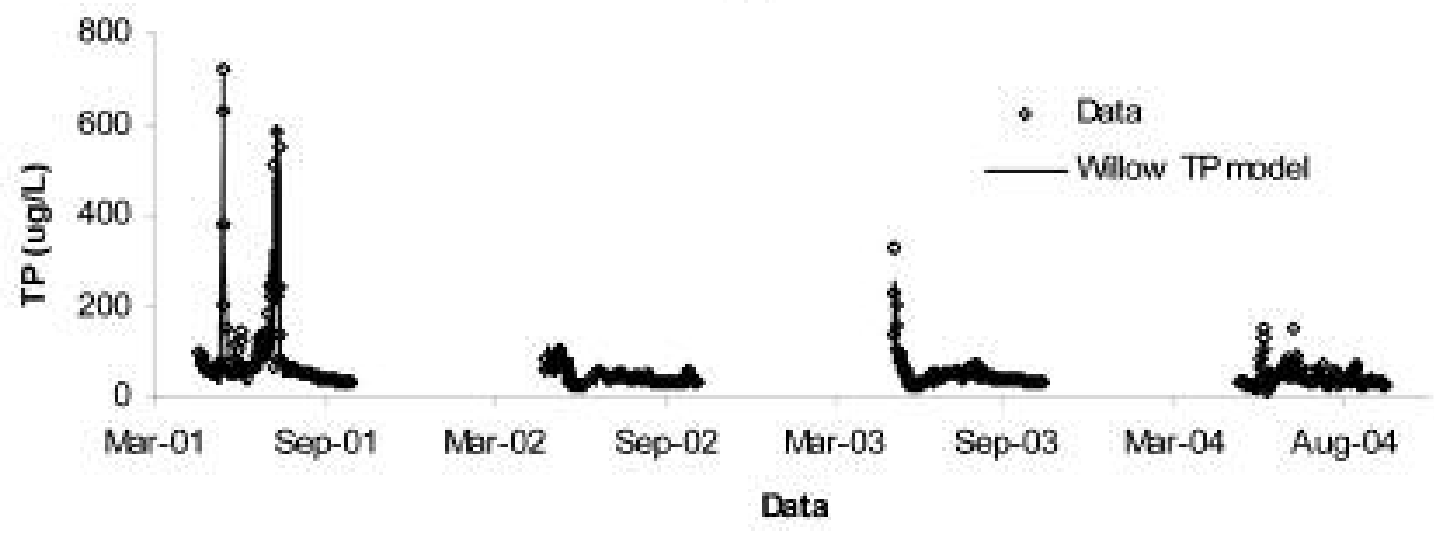

(b)

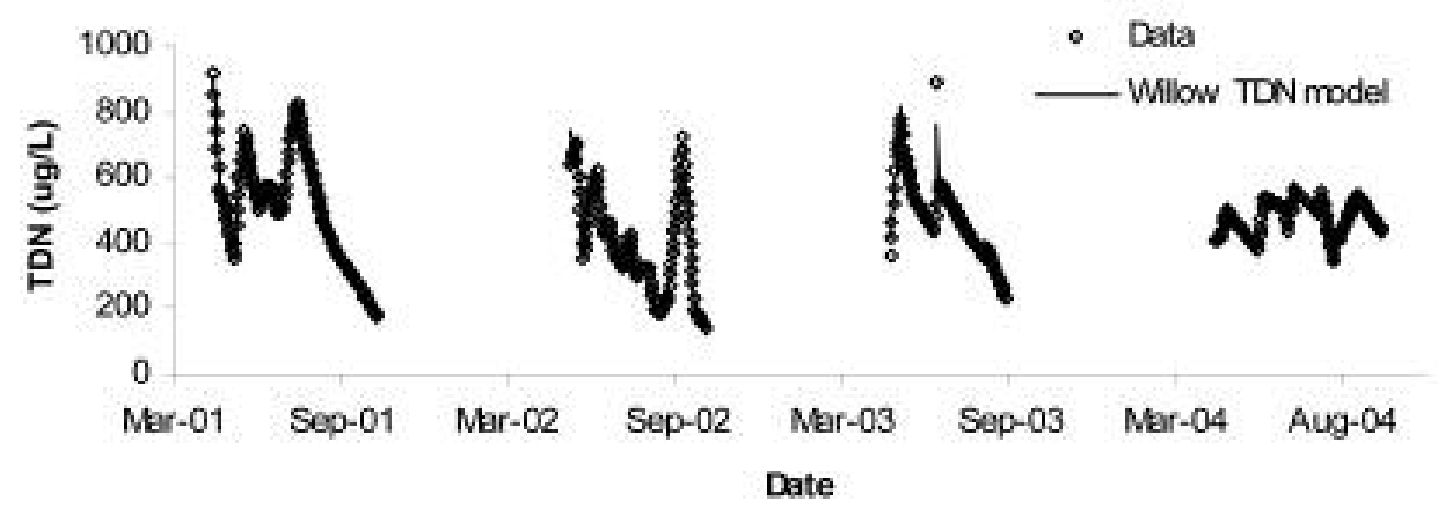

(c)

Fig. 1. Time series plot of measured and ANN predicted (a) streamflow (Q), (b) total phosphorus (TP), and (c) total dissolved nitrogen (TDN) for the Willow watershed.

modelling watersheds in an FMA-scale landbase. The use of MODIS-derived VIs has played an important role in representing phosphorus and nitrogen dynamics within the soil/vegetation phases in the developed water quality models. For example, changes to the vegetation canopy after wildfire in the Burnt Pine watershed (burned in 1998) are captured by the MODIS-derived EVI (Fig. 2). Higher EVI values indicate higher density of vegetation canopy. Compared to the EVI of the Willow watershed, the EVI of the Burnt Pine watershed was lower and demonstrated an increasing trend from 2001 


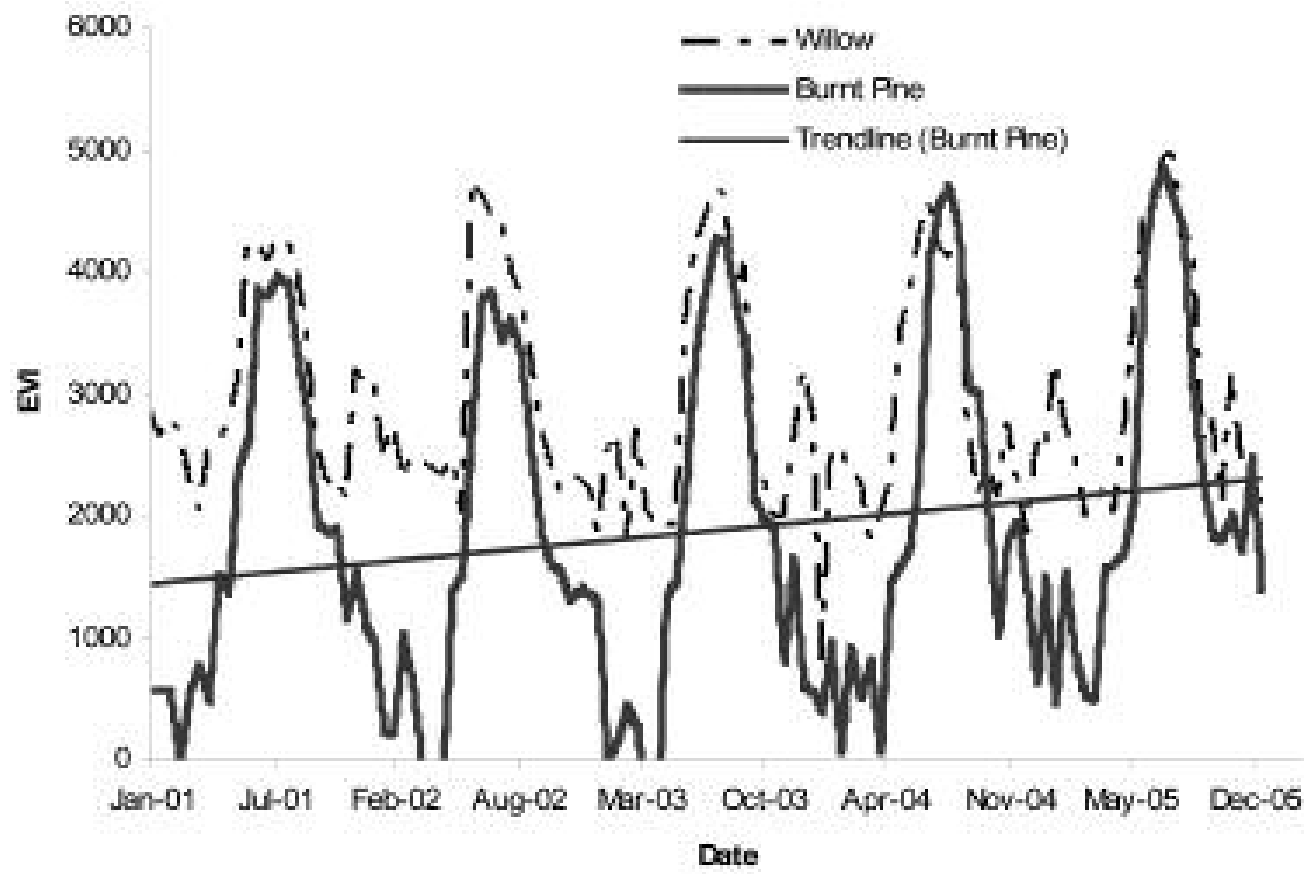

Fig. 2. Comparison of enhanced vegetation index (EVI) for the Willow and Burnt Pine watersheds from 2001 to 2005.

through 2005, which was resulted from the recovery of vegetation with time since disturbance (Fig. 2). The following section proposes a plan to extrapolate the application of the currently developed models to the entire MWFP FMA area.

\section{A Framework to Include Modelling in the DFMP Process} The goal of the FORWARD Project is to develop an improved decision support tool (essentially integrated streamflow and water quality models), which is capable of predicting changes in streamflow and water quality parameters as a result of proposed spatial and temporal patterns of forest harvesting. The improved decision support tool will be incorporated into MWFP's next DFMP to provide the capability to limit and control disturbance effects on water resources in the MWFP FMA area. This task is challenging, due to our immature understanding of the hydrological, biological and chemical mechanisms that control contaminant transport at the large watershed scale, as well as the lack of pertinent data for model calibration. Providing the human and infrastructure resources to gauge streamflow and measure water quality in all watersheds of interest in an FMA area is impractical, thus a class of models that could simulate the response of ungauged watersheds by relying on easily accessible information (like meteorological and RS inputs) is important to forest management planning. The previously described ANN models use readily available, easily accessed meteorological information and public-domain free-of-cost information as model inputs. Such models can have a good chance of application in ungauged watersheds due to the relative ease of obtaining these inputs for an entire FMA area. However, initial results from the FORWARD modelling efforts suggest that the key to obtaining good model predictions on unseen data is the availability of representative data for model training (including wet, dry, and normal conditions), and the key for successful model transferability from one watershed to the other is hydrologic similarity. Thus, the following steps summarize the proposed FORWARD approach toward incorporating water quantity and quality modelling in the MWFP DFMP process:

1. Delineate the digital elevation model (DEM) of the MWFP FMA area into first order watersheds $\left(\sim 5 \mathrm{~km}^{2}\right)$ using the eight-direction pour-point algorithm and a reasonable threshold for flow accumulation. This task is already completed and details are presented in Prepas et al. (2008).

2. Use rainfall interpolation techniques like kriging and inverse distance weighted interpolation techniques to estimate daily rainfall intensity in the centroid of each watershed using data from surrounding weather stations (fire towers, Environment Canada, and FORWARD project stations). FORWARD researchers have established the interpolation algorithm (Nour et al. 2006a). The interpolation weights can be assumed to be fixed with time, and thus can be used for future scenario simulations.

3. Formulate streamflow (Q), TSS and nutrient models for several of the 16 FORWARD experimental watersheds and validate with the remaining watersheds. A series of combinations of calibration and validation watersheds will be examined to assure model stability and parsimony. This process is still ongoing. For each model to be constructed, the following must be done: (1) MODIS images must be downloaded from NASA; (2) data quality has to be 

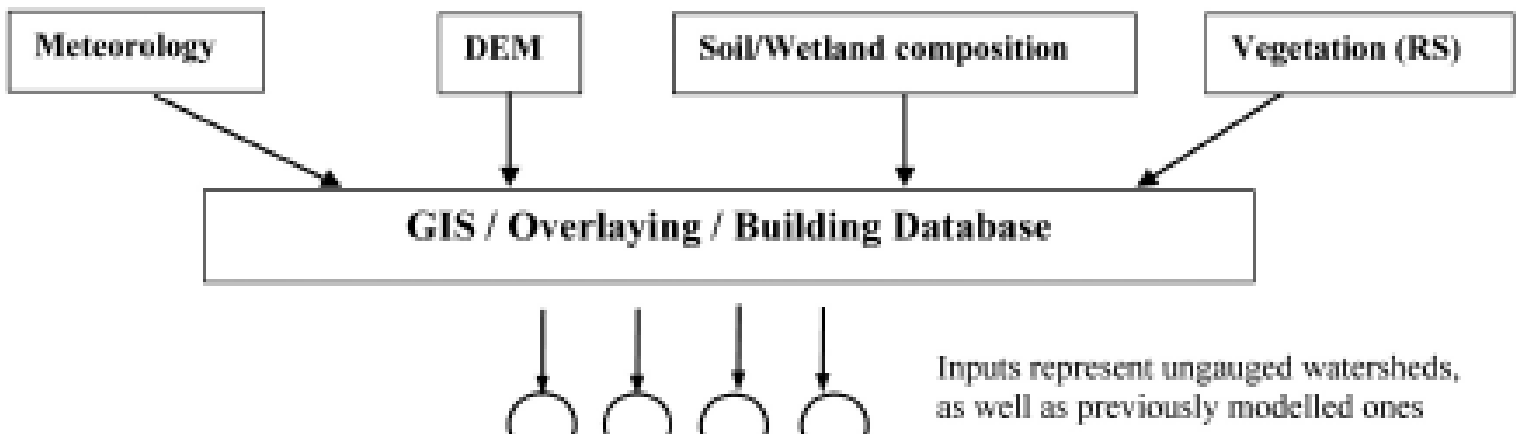

Kohonen NN

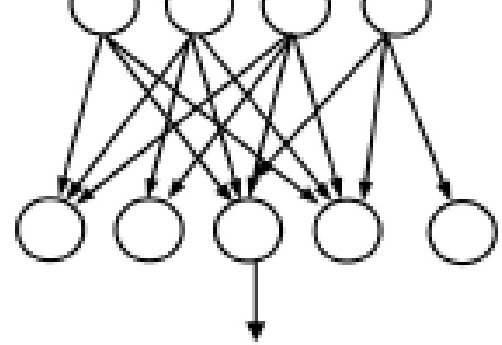
s well as previously modelled ones

The ungauged watershed will be modelled with the models trained

by watersheds falling into its same group

Fig. 3. A framework to model ungauged watersheds using artificial neural network (ANN) models. DEM: digital elevation model, RS: remote sensing, GIS: geographical information systems, NN: neural network.

assessed; (3) a yearly stack of images will be constructed for each spectral band of importance (e.g., red, near infrared, mid-infrared, and blue bands) using Erdas Imagine image processing software (from Leica Geosystems); (4) map algebra will be used to calculate relevant VIs that will later serve as inputs to the water quality models; (5) the DEM-derived watersheds will be overlapped on the satellite images to extract relevant VIs for each delineated watershed; (6) cross correlation and spectral analyses will be used to identify time-lagged inputs and feed the model with Q/TSS/nutrient hystereses loops, respectively; and (7) different ANN models will be formulated for predicting $\mathrm{Q}$, TSS and nutrient concentrations for the FORWARD experimental watersheds.

5. The previously delineated watersheds, including the FORWARD study watersheds, will be grouped into different categories according to hydrologic homogeneity in term of VIs, average slope, $\%$ wetland composition, yearly precipitation, and basin area (Fig. 3). It is proposed to use an advanced classification technique (Kohonen neural networks; Kohonen 1982) to classify the MWFP FMA area delineated watersheds into groups of hydrologically similar watersheds. Data must be collected for a member of each group where none of the FORWARD study watersheds exist. Models are to be calibrated for these additional watersheds as described in No. 3 above. This results in a calibrated model for each group of watersheds.

6. Each calibrated model will then be run for all the watersheds falling into its group of similar watersheds. Upon successful implementation of models to the whole FMA area, scenario-based analysis that forces harvesting distur- bance on the landbase will be fed to the models to identify the impact of different land use activities on water quality and quantity. To design these scenarios, a relation has to be established between VIs (currently used in modelling) and typically used vegetation metrics (e.g., timber volume, average age, height, and diameter at breast height). This relation can be used to translate vegetation cut into values of VIs that can be fed to the models to predict changes in streamflow, water-phase solids, and nutrients in response to harvesting scenarios.

The previous demonstration will finally be repeated with a hybrid ANN/SWAT modelling approach, which would likely create boundaries and reduce the number of parameters for the ANN modelling (a data-driven approach) based on the conceptual representation of the SWAT model (a conceptually based approach) and thus make it easier for ANN parameter estimation.

\section{Conclusions}

Over the past six years, the FORWARD research project has developed a detailed database of soil properties, streamflow and water quality within the MWFP FMA area and a better understanding of the impact of land-based activities on water resources. Simulation models capable of modelling initial streamflow, TSS and nutrient concentrations have been developed and tested on pilot-scale forested watersheds near Whitecourt, Alberta. To apply these models on a full-scale industrial FMA area, it is necessary to adapt them to be less data-intensive and to provide the means to incorporate these models in operational forest management and planning. Therefore, FORWARD attempted to rely on one physically based 
approach to understand the biological, geological, chemical, and physical behaviours of the system, and one data-driven approach, which is flexible in terms of data requirements, to develop a modelling tool that is less data-intensive. In addition, attempts to link both approaches are ongoing in order to capitalize on the strengths of each technique.

To date, FORWARD researchers have made significant modifications to the SWAT model to better model watersheds located in forested ecosystems. More modifications are underway. They developed a step-by-step framework for modelling time-correlated variables using $\mathrm{ANN}$, a protocol for utilizing RS information in water quality modelling, and they have applied the developed models successfully in experimental watersheds on the Boreal Plain.

The experience gained from implementing ANN and SWAT models in experimental watersheds will pave the road for further development towards a robust technique for utilizing RS data at the broader FMA scale. The results of the model application within the MWFP FMA area will be documented and included in the company's next DFMP. These efforts will provide a leading example for similar forest industry companies on how to predict and mitigate disturbance on the landscape wisely, so that water quality is not impaired. This work will also likely provide guidelines for including such modelling tools in operational forest management and planning for possible use by other forest industry companies.

\section{Acknowledgements}

The FORWARD project is funded by the Natural Sciences and Engineering Research Council of Canada (CRD and Discovery Grant Programs) and Millar Western Forest Products Ltd., as well as the Canada Foundation for Innovation, Blue Ridge Lumber Inc. (a Division of West Fraser Timber Company Ltd.), Alberta Newsprint Company (ANC Timber), Vanderwell Contractors (1971) Ltd., the Living Legacy Research Program, and the Ontario Innovation Trust.

\section{References}

Alp, M. and H.K. Cigizoglu. 2007. Suspended sediment load simulation by two artificial neural network methods using hydrometeorological data. Environ. Model. Soft. 22: 2-13.

Arnold, J.G., R. Srinivasan, R.S. Muttiah and J.R. Williams. 1998. Large area hydrologic modeling and assessment - Part 1: Model development. J. Am. Water Resour. Assoc. 34: 73-89.

Arnold, J.G., R. Srinivasan, T.S. Ramanarayanan and M. Di Luzio. 1999. Water resources of the Texas Gulf Basin. Water Sci. Technol. 39: 121-133.

Beasley, D.B., L.F. Huggins and E.J. Monke. 1980. ANSWERS - A model for watershed planning. Trans. ASAE 23: 938-944.

Bingneer, R.L., F.D. Theurer, R.G. Cronshey and R.W. Darden. 2001. AGNPS 2001 [online]. Available from http://msa.ars.usda. gov/ms/oxford/nsl/AGNPS.html.

Bouraoui, F. and T.A. Dillaha. 1996. ANSWERS-2000: Runoff and sediment transport model. J. Environ. Eng.-ASCE 122: 493-502.

Chen, J. and B.J. Adams. 2006. Integration of artificial neural networks with conceptual models in rainfall-runoff modeling. J. Hydrol. 318: 232-249.

Cheng, Y.B., P.J. Zarco-Tejada, D. Riano, C.A. Rueda and S.L. Ustin. 2006. Estimating vegetation water content with hyperspectral data for different canopy scenarios: Relationships between AVIRIS and MODIS indexes. Remote Sens. Environ. 105: 354-366.

Cigizoglu, H.K. and M. Alp. 2006. Generalized regression neural network in modelling river sediment yield. Adv. Eng. Soft. 37: 63-68.
Cigizoglu, H.K. and O. Kisi. 2006. Methods to improve the neural network performance in suspended sediment estimation. J. Hydrol. 317: 221-238.

Cook, D.J., W.J. Dickinson and R.P. Rudra. 1985. GAMES-the Guelph Model for Evaluating the Effects of Agricultural Management Systems in Erosion and Sedimentation. User's Manual. Guelph, ON.

Dakou, E., P.L.M. Goethals, T. D'Heygere, A.P. Dedecker, W. Gabriels, N. De Pauw and M. Lazaridou-Dimitriadou. 2006. Development of artificial neural network models predicting macroinvertebrate taxa in the river Axios (Northern Greece). Annales De Limnologie-Int. J. Limnol. 42: 241-250.

Dawson, C.W. and R.L. Wilby. 2001. Hydrological modelling using artificial neural networks. Progr. Phys. Geogr. 25: 80-108.

Di Luzio, M., J.G. Arnold and R. Srinivasan. 2005. Effect of GIS data quality on small watershed stream flow and sediment simulations. Hydrol. Proc. 19: 629-650.

Diamantopoulou, M.J., P.E. Georgiou and D.M. Papatnichail. 2007. Performance of neural network models with Kalman learning rule for flow routing in a river system. Fresenius Environ. Bull. 16: 1474-1484. Donnelly-Makowecki, L.M. and R.D. Moore. 1999. Hierarchical testing of three rainfall-runoff models in small forested catchments. J. Hydrol. 219: 136-152.

Elhatip, H. and M.A. Komur. 2008. Evaluation of water quality parameters for the Mamasin dam in Aksaray City in the central Anatolian part of Turkey by means of artificial neural networks. Environ. Geol. 53: 1157-1164.

Grunwald, S. and C. Qi. 2006. GIS-based water quality modeling in the Sandusky Watershed, Ohio, USA. J. Am. Water Resour. Assoc. 42: 957-973.

Hauhs, M., C. Neal, R. Hooper and N. Christophersen. 1996. Summary of a workshop on ecosystem modeling: The end of an era? Sci. Total Environ. 183: 1-5.

Johanson, R.C., J.C. Imhoff, J.L. Kittle and A.S. Donigian. 1984. Hydrological Simulation Program-FORTRAN (HSPF) User's Manual. U.S. Environmental Protection Agency, Athens, GA.

Justice, C.O., E. Vermote, J.R.G. Townshend, R. DeFries, D.P. Roy, D.K. Hall, V.V. Salomonson, J.L. Privette, G. Riggs, A. Strahler, W. Lucht, R.B. Myneni, Y. Knyazikhin, S.W. Running, R.R. Nemani, Z.M. Wan, A.R. Huete, W. van Leeuwen, R.E. Wolfe, L. Giglio, J.P. Muller, P. Lewis and M.J. Barnsley. 1998. The Moderate Resolution Imaging Spectroradiometer (MODIS): Land remote sensing for global change research. IEEE Trans. Geosci. Remote Sens. 36: 1228-1249.

Khalil, A., M.N. Almasri, M. McKee, and J.J. Kaluarachchi. 2005. Applicability of statistical learning algorithms in groundwater quality modeling. Water Resour. Res. 41: Art. No. W05010.

Kohonen, T. 1982. Self-organized formation of topologically correct feature maps. Biol. Cybern. 43: 59-69.

Koponen, S., K. Kallio, J. Pulliainen, J. Vepsalainen, T. Pyhalahti and M. Hallikainen. 2004. Water quality classification of lakes using 250-m MODIS data. IEEE Geosci. Remote Sens. Lett. 1: 287-291.

Lek, S., M. Guiresse and J.-L. Giraudel. 1999. Predicting stream nitrogen concentration from watershed features using neural networks. Water Res. 33: 3469-3478.

Li, X., M.H. Nour, D.W. Smith and E.E. Prepas. 2008. Modelling nitrogen composition in streams on the Boreal Plain using Genetic Adaptive General Regression Neural Networks. J. Environ. Eng. Sci. (Under review).

Maier, H.R. and G.C. Dandy. 2000. Neural networks for the prediction and forecasting of water resources variables: a review of modelling issues and applications. Environ. Model. Soft. 15: 101-124.

Maier, H.R., M.D. Burch and M. Bormans. 2001. Flow management strategies to control blooms of the cyanobacterium, Anabaena circinalis, in the River Murray at Morgan, South Australia. Regul. Rivers Res. Manage. 17: 637-650.

Maier, H.R., G.B. Kingston, T. Clark, A. Frazer and A. Sanderson. 2004. Risk-based approach for assessing the effectiveness of flow 
management in controlling cyanobacterial blooms in rivers. River Res. Appl. 20: 459-471.

Matejicek, L., L. Benesova and J. Tonika. 2003. Ecological modelling of nitrate pollution in small river basins by spreadsheets and GIS. Ecol. Model. 170: 245-263.

Michaud, J. and S. Sorooshian. 1994. Comparison of simple versus complex disturbed runoff models on a midsized semiarid watershed. Water Resour. Res. 30: 593-605.

Muleta, M.K. and J.W. Nicklow. 2005. Decision support for watershed management using evolutionary algorithms. J. Water Resour. Plan. Manage. -ASCE 131: 35-44.

National Aeronautics and Space Administration (NASA). 2007. Data Gateway Interface [online]. Available from http://modis.gsfc. nasa.gov/ [cited 15 June 2007].

Ning, S.K., N.B. Chang, K.Y. Jeng and Y.H. Tseng. 2006. Soil erosion and non-point source pollution impacts assessment with the aid of multi-temporal remote sensing images. J. Environ. Manage. 79: 88-101.

Nour, M.H., A. Khan, D.W. Smith, and M.G. El-Din. 2005. On the potential of satellite derived vegetation phenology for watershed nutrient modelling: a neural network approach. Proceedings of the Water Environment Federation, WEFTEC ${ }^{\circledR} 2005$. Washington, DC $23 \mathrm{p}$.

Nour, M.H., D.W. Smith and M.G. El-Din. 2006a. Geostatistical mapping of precipitation: Implications for rain gauge network design. Water Sci. Technol. 53: 101-110.

Nour, M.H., D.W. Smith, M.G. El-Din and E.E. Prepas. 2006b. Neural networks modelling of streamflow, phosphorus, and suspended solids: application to the Canadian Boreal forest. Water Sci. Technol. 53: 91-99.

Nour, M.H., D.W. Smith, M.G. El-Din and E.E. Prepas. 2006c. The application of artificial neural networks to flow and phosphorus dynamics in small streams on the Boreal Plain, with emphasis on the role of wetlands. Ecol. Model. 191: 19-32.

Nour, M.H., D.W. Smith, M.G. El-Din and E.E. Prepas. 2006d. Artificial neural networks and time series modelling of TP concentration in boreal streams: a comparative approach. J. Environ. Eng. Sci. 5 (Suppl. S1): 39-52.

Nour, M.H., D.W. Smith, M.G. El-Din and E.E. Prepas. 2008a. Towards a generic neural network model for the prediction of daily streamflow in ungauged Boreal Plain watersheds. J. Environ. Eng. Sci. (In press)

Nour, M.H., D.W. Smith, M.G. El-Din and E.E. Prepas. 2008b. Effect of Watershed Subdivision on Water-Phase Phosphorus Modelling: An Artificial Neural Network Modelling Application. J. Environ. Eng. Sci. (In press).

Olivera, F., M. Valenzuela, R. Srinivasan, J. Choi, H.D. Cho, S. Koka and A. Agrawal. 2006. ArcGIS-SWAT: A geodata model and GIS interface for SWAT. J. Am. Water Resour. Assoc. 42: 295-309.

Prepas, E.E., G. Putz, D.W. Smith, J.M. Burke and J.D. MacDonald. 2008. The FORWARD Project: Objectives, framework and initial integration into the Detailed Forest Management Plan process in Alberta. For. Chron. 84(3): 330-337.

Putz, G., J.M. Burke, D.W. Smith, D.S. Chanasyk, E.E. Prepas and E. Mapfumo. 2003. Modelling the effects of boreal forest landscape management upon streamflow and water quality: Basic concepts and considerations. J. Environ. Eng. Sci. 2 (Suppl. S1): 87-101.

Qi, C. and S. Grunwald. 2005. GIS-based hydrologic modeling in the Sandusky watershed using SWAT. Trans. ASAE 48: 169-180.

Rudra, R.P., S.C. Negi and N. Gupta. 2005. Modelling approaches for subsurface drainage water quality management. Water Qual. Res. J. Can. 40: 71-81.

Rumelhart, D.E. and J.L. McClelland. 1986. Parallel distributed processing: explorations in the microstructure of cognition. Vol. 2. MIT Press, Cambridge, MA.

Santhi, C., R.S. Muttiah, J.G. Arnold and R. Srinivasan. 2005. A GIS-based regional planning tool for irrigation demand assessment and savings using SWAT. Trans. ASAE 48: 137-147.

Sharpley, A.N., and Williams, J.R. 1990. EPIC-Erosion/Productivity Impact Calculator: I. Model Documentation, Tech. Bull.

Skidmore, A.K. 2002. Introduction. In A. Skidmore (ed.). Environmental Modelling with GIS and Remote Sensing. Taylor \& Francis Inc., New York.

Smith, D.W., J.S. Russell, J.M. Burke and E.E. Prepas. 2003a. Expanding the forest management framework in the province of Alberta to include landscape-based research. J. Environ. Eng. Sci. 2 (Suppl. S1): 15-22.

Smith, D.W., E.E. Prepas, G. Putz, J.M. Burke, W.L. Meyer and I. Whitson. 2003b. The Forest Watershed and Riparian Disturbance study: a multi-discipline initiative to evaluate and manage watershed disturbance on the Boreal Plain of Canada. J. Environ. Eng. Sci. 2 (Suppl. S1): 1-13.

Srivastava, P., J.N. McVair and T.E. Johnson. 2006. Comparison of process-based and artificial neural network approaches for streamflow modeling in an agricultural watershed. J. Am. Water Resour. Assoc. 42: 545-563.

Tayfur, G. and V. Guldal. 2006. Artificial neural networks for estimating daily total suspended sediment in natural streams. Nordic Hydrol. 37: 69-79.

Teles, L.O., V. Vasconcelos, E. Pereira and M. Saker. 2006. Time series forecasting of cyanobacteria blooms in the Crestuma Reservoir (Douro River, Portugal) using artificial neural networks. Environ. Manage. 38: 227-237.

Tsoukalas, L.H. and R.E. Uhrig. 1997. Fuzzy and Neural Approaches in Engineering. Wiley-Interscience, New York.

Wagener, T. 2005. Watershed Modelling. In Water Encyclopedia. John Wiley \& Sons, Inc.

Wang, M.X., G.D. Liu, W.L. Wu, Y.H. Bao and W.N. Liu. 2006. Prediction of agriculture derived groundwater nitrate distribution in North China Plain with GIS-based BPNN. Environ. Geol. 50: 637-644.

Wattenbach, M., F. Hattermann, R. Weng, F. Wchsung, V. Krysanova and F. Badeck. 2005. A simplified approach to implement forest eco-hydrological properties in regional hydrological modelling. Ecol. Model. 187: 40-59.

Wilcox, B.P., W.J. Rawls, D.L. Brakensiek and J.R. Wight. 1990. Predicting runoff from rangeland catchments: A comparison of two models. Water Resour. Res. 26: 2401-2410. 